\title{
Further study on the relationships of the surface tension coefficient of water and the temperature
}

\author{
Shengxian Wei, ${ }^{1, a}$, Fene $\mathrm{Hu}^{2}$, Youming Shi ${ }^{1}$ \\ ${ }^{1}$ College of Physics and Electronic Engineering, Qujing Normal University, Qujing 655011, China; \\ ${ }^{2}$ College of Chemistry and Chemical Engineering, Qujing Normal University, Qujing 655011, China. \\ ${ }^{\mathrm{a} C}$ Corresponding author: wsx_8600@163.com
}

Keywords: Water; Surface tension coefficient; Temperature; Linear fit; Nonlinear quadratic fit

\begin{abstract}
For convenient test comparisons and engineering applications, the relationships between the surface tension coefficient of water and the temperature were analyzed by using the linear fit and the nonlinear quadratic fit based on a number of experimental data from literatures. The new relationships of the experimental values and the temperatures have been built. The results show that the percentage of the data collected is $77.11 \%$ in $0-30^{\circ} \mathrm{C}$. The deviations of the calculated values of the linear fit and the nonlinear quadratic fit relationships and the recognized values are small and they are respectively in $[-0.465,0.365] \mathrm{mN} / \mathrm{m}$ and $[0.128,0.180] \mathrm{mN} / \mathrm{m}$. The calculated values of the linear fit and nonlinear quadratic fit relationships are highly consistent with the recognized values. Moreover, the accuracy of the nonlinear quadratic fit equation is higher than that of the linear fit equation. In addition, $22.89 \%$ of the data collected are in $30-80^{\circ} \mathrm{C}$. The deviations between the calculated values and the recognized values are relatively large and they are respectively in $[0.365$, $0.692] \mathrm{mN} / \mathrm{m}$ and $[0.170,1.180] \mathrm{mN} / \mathrm{m}$.
\end{abstract}

\section{Introduction}

The liquid surface has a tendency to shrink because of the interaction of molecular force. This trend can be characterized by the liquid surface tension. The magnitude of the liquid surface tension can be described by the surface tension coefficient. The liquid surface tension has important applications in industry, agriculture, medicine, thermology, chemistry, and other areas of daily life. Therefore, theoretical and experimental studies of the liquid surface tension coefficient have become an important research topic. Temperature is one of the important factors affecting the liquid surface tension coefficient. The liquid surface tension coefficient decreases with the temperature increase. In recent years, related scholars conducted a number of experimental studies on the relationship between the liquid surface tension coefficient and the temperature [1-6]. However, there is a relatively large deviation between the partial experimental results and the recognized value. The number of the recognized value in the experimental textbook is less and its interval is large. For convenient test comparisons and engineering applications, the relationships between the surface tension coefficient of water and the temperature were analyzed by using the linear fit and the nonlinear quadratic fit methods based on a number of experimental data from the literatures. The new relationships of the experimental values and the temperatures have been built.

\section{Data collections and analyses}

The experimental data collected are published in literatures from the China National Knowledge. To ensure the effectiveness of the data, the difference of the surface tension coefficient of the water and the recognized value does not exceed $\pm 2.0 \mathrm{mN} / \mathrm{m}$. The test temperature and the surface tension coefficient range in $5-80^{\circ} \mathrm{C}$ and $61.02-74.78 \mathrm{mN} / \mathrm{m}$. The percentage and the number of data in each temperature range are shown in Table 1 . Data in Table 1 show that most of the data located between $5-30^{\circ} \mathrm{C}$, and the percentage accounts for $77.11 \%$ of the total number of the data. The number of the 
data in $30-80^{\circ} \mathrm{C}$ accounts for only $22.89 \%$ of the total number of the data. The temperature $t\left({ }^{\circ} \mathrm{C}\right)$, the surface tension coefficient $\alpha(\mathrm{mN} / \mathrm{m})$ and the data source are listed in Table 2.

Table 1 Data distributions

\begin{tabular}{lll}
\hline Temperature range $\left({ }^{\circ} \mathrm{C}\right)$ & Number & Percentage $(\%)$ \\
\hline $5-10$ & 6 & 7.23 \\
$11-19$ & 21 & 25.30 \\
$20-29$ & 37 & 44.58 \\
$30-39$ & 4 & 4.82 \\
$40-49$ & 5 & 6.02 \\
$50-59$ & 6 & 7.23 \\
$60-69$ & 1 & 1.20 \\
$70-80$ & 3 & 3.61 \\
\hline
\end{tabular}

$\underline{\text { Table } 2 \text { Temperature and surface tension coefficient }}$

\begin{tabular}{|c|c|c|c|c|c|}
\hline $\begin{array}{l}t \\
\left({ }^{\circ} \mathrm{C}\right. \\
\text { ) }\end{array}$ & $\begin{array}{l}\alpha \\
(\mathrm{mN} / \mathrm{m})\end{array}$ & $\begin{array}{l}\text { Sourc } \\
\mathrm{e}\end{array}$ & $\begin{array}{l}t \\
\left({ }^{\circ} \mathrm{C}\right)\end{array}$ & $\begin{array}{l}\alpha \\
(\mathrm{mN} / \mathrm{m})\end{array}$ & $\begin{array}{l}\text { Sourc } \\
\mathrm{e}\end{array}$ \\
\hline 25 & 72.54 & [1] & 40 & 68.5 & [27] \\
\hline 10 & 73.2 & [3] & 60 & 65 & [27] \\
\hline 20 & 71.7 & [3] & 80 & 61.8 & [27] \\
\hline 30 & 70.1 & [3] & 15 & 72.85 & [28] \\
\hline 40 & 68.6 & [3] & 20 & 71.8 & [29] \\
\hline 50 & 67 & [3] & 20 & 71.8 & [30] \\
\hline 60 & 65.4 & [3] & 20 & 72.49 & [31] \\
\hline 70 & 63.9 & [3] & 25 & 72.48 & [32] \\
\hline 5 & 74.1 & [5] & 25 & 71.88 & [33] \\
\hline 20 & 71.9 & [5] & 24.3 & 72.58 & [34] \\
\hline 40 & 68.5 & [5] & 10 & 74.22 & [35] \\
\hline 60 & 65 & [5] & 11 & 74.02 & [35] \\
\hline 80 & 61.8 & [5] & 12 & 73.93 & [35] \\
\hline 20 & 73.11 & [7] & 13 & 73.78 & [35] \\
\hline 15 & 73.6 & [8] & 14 & 73.64 & [35] \\
\hline 20 & 72.1 & [9] & 15 & 73.49 & [35] \\
\hline 20 & 73.29 & [9] & 16 & 73.34 & [35] \\
\hline 40 & 69.78 & [9] & 17 & 73.19 & [35] \\
\hline 80 & 61.02 & [9] & 18 & 73.05 & [35] \\
\hline 20 & 71.5 & {$[10]$} & 19 & 72.9 & [35] \\
\hline 19 & 72 & [11] & 20 & 72.75 & [35] \\
\hline 26 & 70.36 & [12] & 25 & 72.54 & [36] \\
\hline 25 & 71.4 & [13] & 25 & 71.48 & [37] \\
\hline 25 & 71.8 & [14] & 22 & 73.4 & [38] \\
\hline 15 & 72.36 & [15] & 14.9 & 73.04 & [39] \\
\hline 20 & 73.2 & [16] & 24.5 & 72.61 & [40] \\
\hline 20 & 71.62 & [17] & 10 & 74.23 & [40] \\
\hline 18 & 72.86 & [18] & 20 & 72.75 & [40] \\
\hline 21 & 73.6 & [19] & 25 & 71.99 & [40] \\
\hline 25 & 72.46 & [20] & 50 & 67.94 & [40] \\
\hline 20 & 73.11 & [21] & 10 & 74.22 & [41] \\
\hline 30 & 70.8 & [22] & 20 & 72.82 & [41] \\
\hline 10 & 74.1 & [23] & 30 & 71.02 & [41] \\
\hline 12 & 73.87 & [23] & 40 & 69.57 & [41] \\
\hline 14 & 73.65 & [23] & 50 & 67.98 & [41] \\
\hline 16 & 73.28 & [23] & 20 & 71.62 & [42] \\
\hline 18 & 73.09 & [23] & 19 & 74 & [43] \\
\hline 20 & 72.7 & [23] & 20 & 72.3 & [44] \\
\hline 25 & 72.2 & [24] & 30.1 & 71.1 & [45] \\
\hline
\end{tabular}




\begin{tabular}{llllll}
\hline 24. & 72.54 & {$[25]$} & 29.75 & 72.2 & {$[46]$} \\
3 & & & & & \\
12. & 74.78 & {$[26]$} & 20 & 71.2 & {$[47]$} \\
9 & 71.9 & {$[27]$} & & & \\
\hline
\end{tabular}

\section{Data processing and analyses}

The relationships between the surface tension coefficient of water and the temperature were analyzed by using the linear fit and the nonlinear quadratic fit methods in Fig. 1 and Fig. 2. In Figures 1 and 2, $\mathrm{N}$ is the number of data points, $\mathrm{R}\left(\mathrm{R}^{2}\right)$ is the correlation coefficient, SD is the standard deviation and $\mathrm{P}$ is the probability (that $\mathrm{R}\left(\mathrm{R}^{2}\right)$ is zero). The linear fit and the nonlinear quadratic fit relationships are respectively as follows:

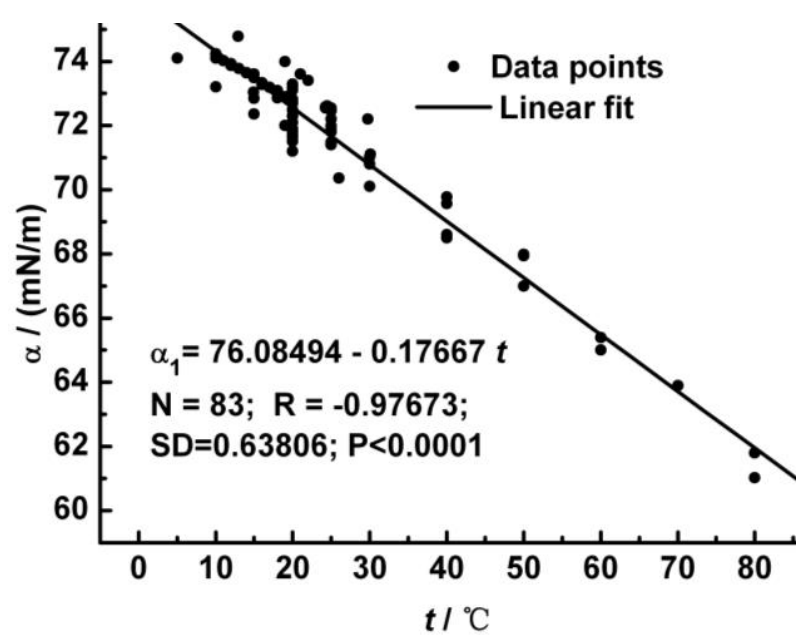

Figure. 1 Linear fit between $\alpha$ and $t$

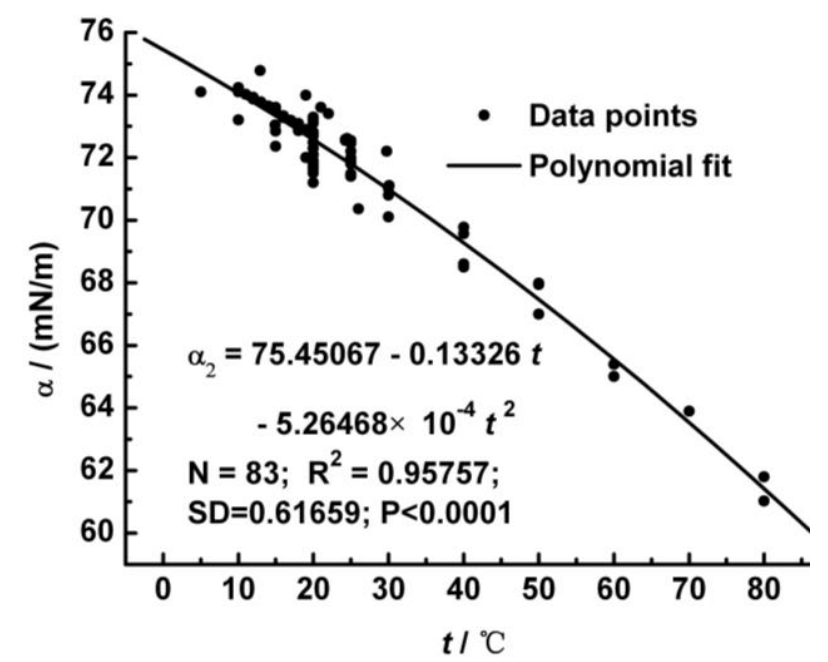

Figure. 2 Nonlinear quadratic fit between $\alpha$ and $t$ 


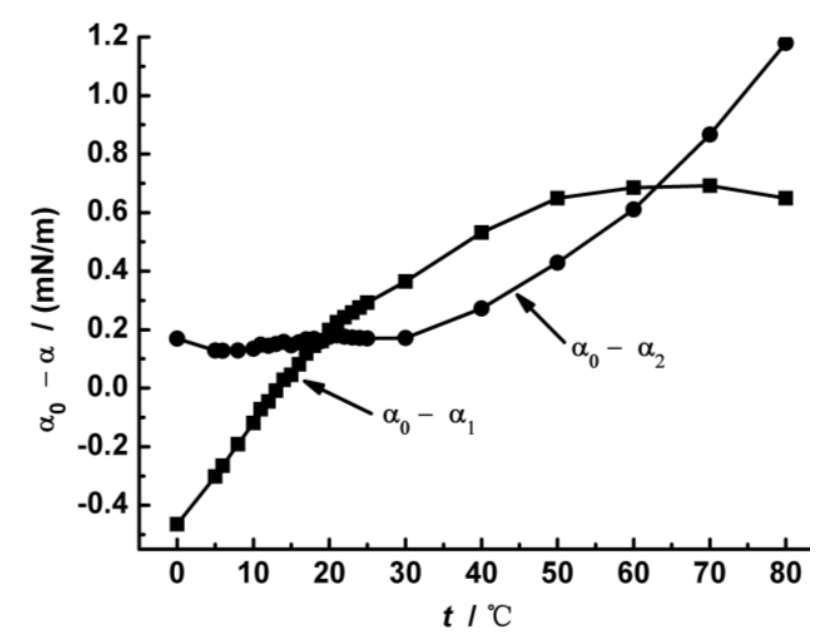

Figure. 3 Difference between $\alpha_{0}$ and $\alpha_{1}\left(\alpha_{2}\right)$

$$
\begin{gathered}
\alpha_{1}=76.08494-0.17667 t \quad(\mathrm{R}=-0.97673) \\
\alpha_{2}=75.45067-0.13326 t-5.26468 \times 10^{-4} t^{2} \quad\left(\mathrm{R}^{2}=0.95757\right)
\end{gathered}
$$

The differences between the recognized values $\alpha_{0}$ [48] and the calculated values $\alpha_{1}\left(\alpha_{2}\right)$ are plotted against the temperature $t$ in Fig.3. Figure 3 shows that the deviation between the recognized values and the calculated values $\alpha_{1}\left(\alpha_{2}\right)$ of the linear fit and nonlinear quadratic fit relationships is relatively small because the recognized value and the experimental value mainly distributed between $0-30^{\circ} \mathrm{C}$. The deviations are respectively in $[-0.465,0.365] \mathrm{mN} / \mathrm{m}$ and $[0.128,0.180] \mathrm{mN} / \mathrm{m}$ for the linear fit and nonlinear quadratic fit. Accordingly, the calculated values of the linear fit and nonlinear quadratic fit relationships are in good agreement with the recognized value in $0-30^{\circ} \mathrm{C}$. Moreover, the accuracy of the nonlinear quadratic fit equation is higher than that of the linear fit equation. Furthermore, the data collected are less in $30-80^{\circ} \mathrm{C}$ and its percentage is $22.89 \%$. There are relatively large deviations between the calculated values and the recognized values and they are respectively in $[0.365,0.692] \mathrm{mN} / \mathrm{m}$ and $[0.170,1.180] \mathrm{mN} / \mathrm{m}$.

\section{Results and conclusions}

The high correlativity relationships between the surface tension coefficient of water and the temperature were built based on the experimental data from the literatures.

The differences between the calculated values of the linear fit and nonlinear quadratic fit relationships and the recognized values are small in $0-30^{\circ} \mathrm{C}$ and they are respectively in $[-0.465,0.365]$ $\mathrm{mN} / \mathrm{m}$ and $[0.128,0.180] \mathrm{mN} / \mathrm{m}$. Therefore, the calculated values are highly consistent with the recognized values. The accuracy of the nonlinear quadratic fit equation is higher than that of the linear fit equation.

The data collected are less in $30-80^{\circ} \mathrm{C}$ and its percentage is $22.89 \%$. The deviations between the calculated values and the recognized values are relatively large and they are respectively in $[0.365$, $0.692] \mathrm{mN} / \mathrm{m}$ and $[0.170,1.180] \mathrm{mN} / \mathrm{m}$.

\section{Acknowledgements}

The work was supported by the Applied Basic Research Project of the Yunnan Province (Grant No. 2013FZ111), the Project for Innovative Research Team (Grant No. TD201301), the Education Reform Project (Grant No. JGXM2012013) and the Superior Quality Course 'Calorifics' (Grant No. YZKC201408) of the Qujing Normal University. 


\section{References}

[1] W. Dai. Physics experimentation, 2011,31(10):29-32.

[2] H. Zhu, R.P. Deng, Y.J. Chen. Physics experimentation, 2009, 29(7):40-42.

[3] X.W. Tan. Journal of Southwest China Normal University (Natural Science), 2007,32(4):115-118.

[4] L.J. Zhang. Journal of Xingyi Normal University for Nationalities, 2013, (3):100-102.

[5] W.H. Ren, Z.Q. Lin, D.L. Peng. Journal of Hunan Agricultural University (Natural Sciences), 2004, 30(1):77-79.

[6] L. Feng, W. Dai. Metrology and Testing Technology,2009,36(4):60-61.

[7] Y.Q. Li, H.J. Zhang. Research and experimentation in laboratory, 2013,32(4):43-46.

[8] X.H. Hao. Physics experimentation, 1992,14(1):41.

[9] F.L. REn, N. Sun, D.M. Wang, et al. Metrology and Testing Technology, 2005,32(12):5-6.

[10] W.S. Chen. Technology wind,2014,3:17-18.

[11] C.Z. Bai, R.B. Chen. Physics experimentation,1998,19(4):8-9.

[12] L.H. Wu. Journal of Jishou University(Natural Science Edition),2009,30(1):74-75,78.

[13] S.C. Zhou,T.K. Guo,Y. Zhou, et al. Physics experimentation,2012,32(12):30-32.

[14] X.S. Leng, H.H. Wang, K.M. Wang. Journal of University of Science and Technology Liaoning, 2008,31(5):466-469.

[15] W.L. Zhao,F. Gao, X.C. Cao, et al. Physical experiment of college,2012,25(1):70-71.

[16] Y.Q. Li. Research and experimentation in laboratory, 2010, 29(8):18-20.

[17] Z.L. Yang. Applied laser, 2004, 24(5):295-298.

[18] Z.Q. Liu, H.X. Feng. Journal of Yan'an University (Natural science edition) ,2008,27(2):34-36.

[19] B. Liang. Journal of Baise University,2011,24(3):81-83.

[20] N.X. Yang, X.H. Wang, K. Cui. Journal of Yan'an University ( Natural science edition),2013, 32(3):38-40.

[21] S.D. Xu, W. Hu, Z.Z. Li, et al. Journal of Hebei North University(Natural Science Edition),2007, 23(5):7-8,28.

[22] Q.L. Yan, D. Li, Y.M. Tang. Experiment science and technology, 2013,11(2):19-21.

[23] Y.K. An, Y.Y. Xu, Y.C. Wang, et al. College physics,2010,29(12):31-33.

[24] W.M. Kong, W.J. Zhao.College physics,2012,31(3):32-34.

[25] Y. Sheng, S.L. Lu, Z.D. Cao. Experiment technology and management,2003,20(1):39-42.

[26] G.Y. Wang, X. Zhang. Journal of transducer technology,2003,22(7):52-54.

[27] X. Yan, L.J. Liang, C. W. Sun. Journal of Zaozhuang University, 2013,30(2):65-70.

[28] X.Y. Zhan. Physical experiment of college, 2014,27(1):83-87.

[29] Q. Zhao. Journal of Anhui Science and Technology University, 2010,24(2):44-47.

[30] L.X. Luo, Y.R. Liu, J.D. Yu, et al. Science and Technology Innovation Herald,2013,29:37,39.

[31] J.W. Han, G.L. Ma. Journal of Binzhou University,2010,26(6):101-103. 
[32] J. Tian, H. Li. College physics,2012,31(10):28-30,41.

[33] G. L. Ma, W.W. Feng. Physics experimentation, 2012,32(3):25-28.

[34] Y.Q. Wang, D.F. Yang. Journal of Yan'an University (Natural Science Edition),2007,26(3): 32-33,38.

[35] G.L. Wang. Medical Information, 2007, 20(8):1349-1351.

[36] W. Dai, P.C. Xu, T.H. Chen, et al. College physics,2011,9:38-40.

[37] J.Cheng, L. Li, K. Liu. China Measurement \& Test,2014,40(3):32-34.

[38] X.J. Mu, Z.X. Liu, J. Chen. College physics,2009,28(6):18-20.

[39] S.L. Wang, M.Z. Ma. College physics,2010,29(3):35-37,43.

[40] P. Lu, Y. Zhu. Physical experiment of college,2013,26(4):30-32.

[41] S.G. Yu. Optical instruments,2003,25(5):3-6.

[42] Z.L. Yang. Journal of Shanxi Normal University(Natural Science Edition), 2000,28(2):119-120.

[43] W. Wang, Q.C. Wei, M. Wang. Gansu Science and Technology, 2004,20(11):130,118.

[44] Y.F. Hu,A. Q. Yao. Physics and Engineering,2005,15(6):38-40.

[45] L.F. Jiao,S.L. Chen. Physics experimentation, 2002,22(7):40-42.

[46] S.F. Xia, D.H. Liu, J.G. Sun, et al. Physics experimentation,2003,23(7):39-41,43.

[47] H.W. Zhao, M.X. Li,S.G. Bai. Physics experimentation,2007,27(7):36-38.

[48] Y.P. Dai, F.F. Wang, S.B. Wang. College Physics Experimentations. Beijing: Enginery industry publishing company,2006,4. 